\title{
A água como elemento de integração transfronteiriça: o caso da Bacia Hidrográfica Mirim-São Gonçalo
}

FER NANDA DE MOURA FER NANDES, ${ }^{I}$ GILBERTO LOGUERCIO COLLARES II e RAFAEL CORTELETTIIII

\section{Introdução}

A EXPERIÊNCIA de cooperação entre Brasil e Uruguai, originada na década de 1960, se apresenta como um caso pioneiro de arranjo intergovernamental voltado para o manejo de bacias hidrográficas transfronteiriças no âmbito da América do Sul. A água, por suas propriedades, se constituiu num elemento integrador em si mesmo, desconhecendo a concepção de território como uma instância político-administrativa formal.

De maneira geral os recursos fluviais e lacustres são percebidos como "limites naturais" na demarcação da linha divisória entre países (Pucci, 2010), como foi o caso da política brasileira de limites ao longo da história (Cervo; Bueno, 2011; Goes Filho, 2015). Do ponto de vista jurídico-diplomático, tal noção coloca a água como um elemento que divide territórios e gera conflitos, quando na verdade deveria ser vista como algo que os une, gerando uma relação de interdependência e integração entre sociedades.

A cooperação estatal no caso da Bacia Hidrográfica Mirim-São Gonçalo foi fundamental na construção da gestão compartilhada da água transfronteiriça. O desenvolvimento de uma visão comum sobre o território, em torno dos múltiplos usos da água, tem um impacto direto no desenvolvimento regional e no adensamento das relações sociais e econômicas entre Brasil e Uruguai.

Neste texto será apresentada uma análise qualitativa da gestão compartilhada da Bacia Mirim-São Gonçalo, como um modelo voltado para o desenvolvimento e a integração regional a partir dos usos da água. Historicamente as relações bilaterais entre Uruguai e Brasil são marcadas pela aproximação e mescla cultural nas regiões de fronteira, pelo entendimento político e pela cooperação econômica. Atualmente, as ações estatais no âmbito do Grupo de 
alto nível Brasil-Uruguai destinam especial atenção à promoção da cooperação fronteiriça nos territórios.

A análise qualitativa terá por base a observação de documentos oficiais brasileiros e uruguaios, apoiada na revisão da literatura disponível acerca do tema. Considerando os objetivos principais desta análise, inicialmente será apresentado o contexto ambiental e socioeconômico da bacia e os aspectos da sua natureza transfronteiriça. Na sequência serão ilustrados marcos institucionais e legais pioneiros de gestão compartilhada desse recurso hídrico, expressos pela criação da Comissão Mista Brasileiro-Uruguaia para o Aproveitamento da Bacia da Lagoa Mirim (CLM) e pela assinatura do Tratado da Lagoa Mirim. Por fim, será apresentada a Agência para o Desenvolvimento da Lagoa Mirim (ALM), ator público presente no território, e como sua atuação pode robustecer o modelo de gestão existente ao promover e aprofundar a coordenação com os demais atores públicos e a sociedade civil. Para tanto, por fim, será descrito e analisado o cenário atual em torno dos usos da água e os desafios ao desenvolvimento da bacia.

\section{A Bacia Hidrográfica Mirim-São Gonçalo}

Desde a década de 1970, o avanço do debate internacional sobre os usos da água ensejou a construção de uma nova concepção de gerenciamento dos recursos hídricos, mediante a elaboração do conceito de bacia hidrográfica como uma unidade territorial com características próprias e indissociáveis (Sant'Anna, 2011). Esse território, limitado por divisores topográficos, capta as águas da chuva e as escoa para um único local. Portanto, a bacia hidrográfica compõe-se basicamente de um conjunto de superfícies e de uma rede de drenagem formada por cursos de água que confluem até resultar um leito único no exutório (Tucci, 2001).

A presença da água define a ocupação, o crescimento e desenvolvimento da atividade humana, das demais espécies animais e vegetais, assim como todas as ações praticadas nesse espaço. Qualquer alteração imposta no mais distante local de uma bacia hidrográfica implica modificações sentidas por todos os seus usuários, percebidas na água que infiltra, que evapora e que flui até a parte mais baixa. Assim, a água se apresenta como elemento integrador, seja do ponto de vista físico, com significativa importância para a preservação e manutenção dos recursos naturais e ecossistemas; seja na sua relação com às distintas atividades desenvolvidas no território, sendo norteadora do desenvolvimento social, econômico e político. Em síntese, "a bacia hidrográfica é o palco unitário de interação das águas com o meio físico, o meio biótico e o meio social, econômico e cultural" (Yassuda, 1993, p.8).

\section{Contexto ambiental}

A Bacia Hidrográfica Mirim-São Gonçalo é um espaço binacional localizado no extremo-sul do Brasil e a leste do Uruguai. Abrange as províncias geomorfológicas da Planície Costeira e do Escudo Uruguaio-Sul-Rio-Grandense (Sema, 2020). Com área de aproximadamente $62.250 \mathrm{~km}^{2}$, é composta de importantes 
cursos d'água que deságuam na Lagoa Mirim e/ou no Canal São Gonçalo. A Lagoa Mirim se assenta sobre a planície costeira e possui uma largura média de 20 $\mathrm{km}$ e $3.750 \mathrm{~km}^{2}$ de superfície, sendo $2.750 \mathrm{~km}^{2}$ em território brasileiro e 1.000 $\mathrm{km}^{2}$ em território uruguaio. Dessa forma a Lagoa Mirim se configura como o principal reservatório natural de água da Bacia Hidrográfica Mirim-São Gonçalo e forma com a Laguna dos Patos o maior complexo lagunar da América do Sul. A conexão entre os dois sistemas se dá através de um canal natural com $76 \mathrm{~km}$ de extensão, chamado de São Gonçalo, que escoa as águas da Lagoa Mirim para a Laguna dos Patos. Porém em épocas de estiagem esse escoamento se inverte e águas salobras fluem da Laguna dos Patos através do Canal São Gonçalo em direção à Lagoa Mirim.

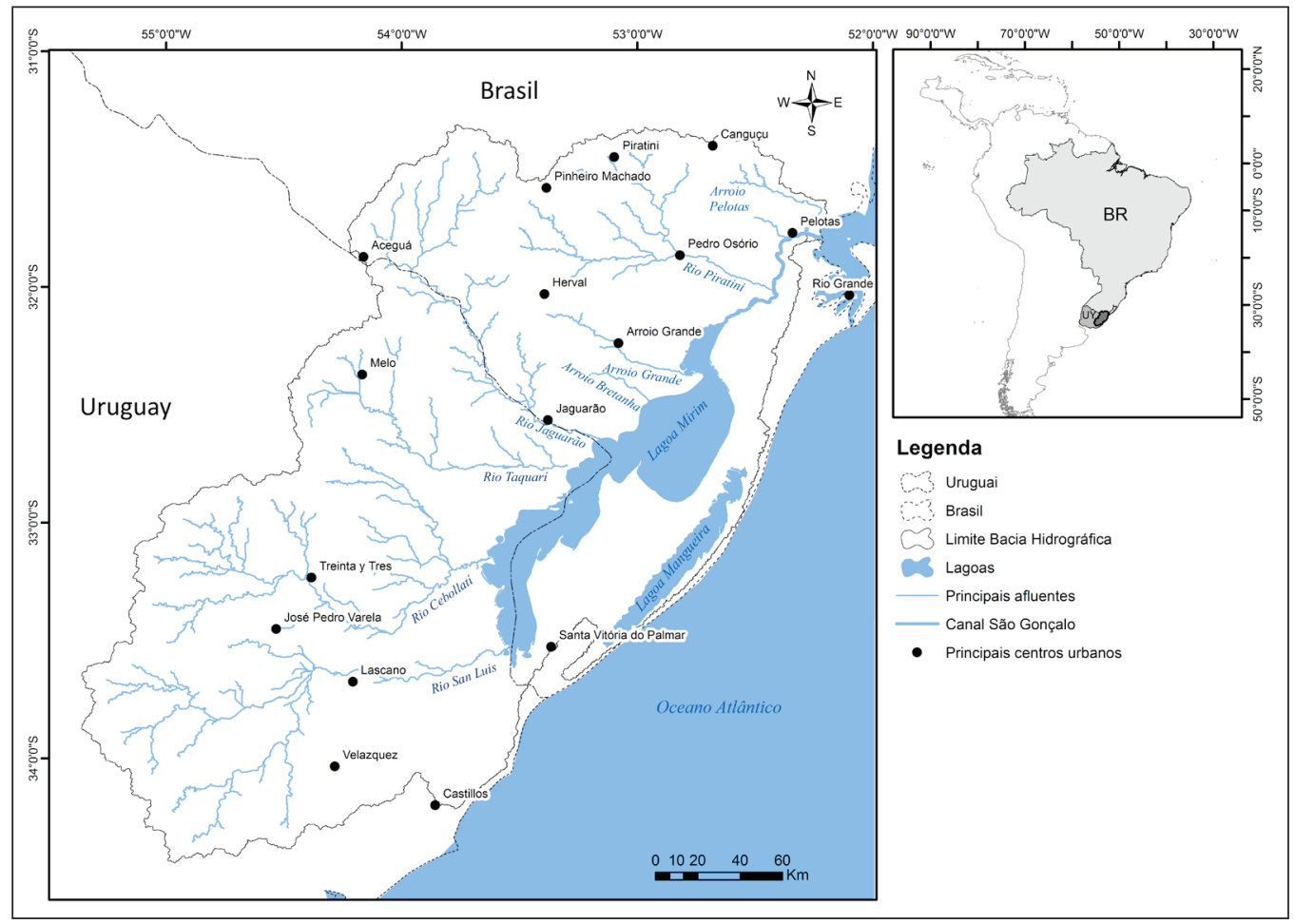

Fonte: Elaboração própria.

Figura 1 - Bacia Hidrográfica Mirim-São Gonçalo, seus principais cursos d'água e centros urbanos.

A Lagoa Mirim e o complexo de áreas úmidas em seu entorno formam uma das principais bacias hidrográficas transfronteiriças da América do Sul, de grande importância ecológica e econômica (Oliveira et al., 2015). A porção da bacia hidrográfica em território uruguaio corresponde a $53 \%$ da área total, e no território brasileiro $47 \%$. A parte uruguaia da bacia hidrográfica corresponde a cerca de $18 \%$ do território nacional, configurando importância geopolítica e ambiental singular. No território brasileiro, a bacia abrange as microrregiões da 
Zona Sul e da Campanha do Rio Grande do Sul (RS), compondo cerca de 13\% da superfície desse estado (Figura 1).

Assim sendo, as abundantes águas doces da bacia constituem-se num ecossistema fechado, com comunicação muito limitada para o exterior através do Canal São Gonçalo. A contribuição da água dos afluentes da Lagoa (30 mil $\left.\mathrm{m}^{3} \mathrm{~s}^{-1}\right)$ é muito maior que a saída para a Laguna dos Patos através do Canal São Gonçalo $\left(4 \mathrm{mil} \mathrm{m}^{3} \mathrm{~s}^{-1}\right)$, confirmando que a Lagoa Mirim atua como um grande reservatório de água doce. A hidrodinâmica na lagoa é controlada pela descarga de seus afluentes, que determinam a variação do seu volume de água, e pelo vento, que controla a evaporação e a circulação da água. A conexão com a Laguna dos Patos e as inversões de fluxo que ocorrem no Canal São Gonçalo representam elementos de fragilidade para os recursos hídricos. Por isso, com recursos da Organização das Nações Unidas (ONU), em um projeto concebido nos anos 1960-1970, foram eliminadas as intermitentes intrusões salinas na Lagoa Mirim, com a construção de uma barragem-eclusa que garante uma reserva de água doce para cerca de um milhão de pessoas e possibilita a agricultura irrigada (Gouvêa et al., 2010).

Os ecossistemas da bacia também são importantes por sua biodiversidade e importância para a conservação em razão de suas diversas paisagens e ecossistemas, distinguindo: 1) a faixa costeira do Atlântico com lagoas e lagunas nos dois países; 2) várias zonas baixas e úmidas associadas a lagoas e florestas com uma rica biodiversidade; 3 ) Bioma do Pampa e matas ciliares e úmidas; e 4) terras altas associadas com o sistema das Serras de Sudeste (Cordeiro; Hasenack, 2009). As áreas úmidas são de grande importância em razão da diversidade de flora e fauna que apresentam e por constituírem também o hábitat de aves migratórias. Da mesma forma, atuam como reguladores naturais do escoamento de rios, amortecendo inundações, promovendo recargas de aquíferos, contribuindo para a melhoria da qualidade da água e tendo valor sociocultural, destacando-se pelas belezas cênicas e paisagísticas (MMA, 2000). Por fim, a situação das áreas protegidas na bacia é muito heterogênea entre os dois países. Reconhecendo seu valor, o governo do Uruguai designou os Bañados del Este um sítio Ramsar e suas zonas úmidas como parte da Reserva da Biosfera da Unesco (Probides, 1999). Do lado brasileiro, a Estação Ecológica do Taim faz parte da rede de Reservas da Mata Atlântica, do Programa MAB da Unesco. Além disso, destacam-se as reservas biológicas estaduais (Mato Grande, Maçarico e Bioma Pampa).

\section{Contexto socioeconômico}

A bacia apresenta disparidades significativas em termos socioeconômicos, tanto comparando cada região em relação ao seu país, mas também comparando a situação da bacia nos dois países.

No Brasil, o Rio Grande do Sul (RS) em termos gerais possui um grau médio de desenvolvimento socioeconômico (Quadro 1). A população da bacia concentra-se especialmente em centros urbanos, atingindo menos de $15 \%$ 
da população localizada em áreas rurais. Nessa população, 52\% são mulheres e cerca de $62,5 \%$ têm idade ativa (> 14 e <65) - todos os dados populacionais são estimativas para o ano de 2018, de acordo com a FEE (2020). Levando em consideração a geração de riqueza por meio do Produto Interno Bruto (PIB), o RS representa 6,4\% do valor nacional, enquanto o PIB per capita está acima da média nacional (R\$37.512,00). Por sua vez, no recorte da bacia, o PIB gerado corresponde a 6,6\% do Estado e o PIB per capita está abaixo da média nacional (R\$ 29.741,00). Na Bacia Mirim-São Gonçalo, o Valor Adicionado Bruto (VAB) no setor primário tem um peso de $8,5 \%$, o setor industrial participa com $5,1 \%$ e os serviços somam 6,8\% dos valores estaduais (FEE, 2020).

Quadro 1 - Dados demográficos e econômicos brasileiros da Bacia Mirim-São Gonçalo

\begin{tabular}{|c|c|c|c|c|c|c|c|}
\hline \multirow{3}{*}{ MUNICÍPIO } & \multicolumn{2}{|l|}{ Área } & & \multicolumn{2}{|l|}{ População } & \multirow{3}{*}{$\begin{array}{c}\text { PIB per } \\
\text { capita (R\$) }\end{array}$} & \multirow{3}{*}{$\begin{array}{r}\text { IDESE } \\
2016\end{array}$} \\
\hline & & & & \multirow{2}{*}{$\begin{array}{l}\text { Total } \\
2018\end{array}$} & \multirow{2}{*}{$\begin{array}{c}\text { Na Bacia } \\
2018\end{array}$} & & \\
\hline & Total $\left(\mathrm{Km}^{2}\right)$ & $\begin{array}{c}\text { na Bacia } \\
\left(\mathrm{Km}^{2}\right)\end{array}$ & $\%$ na Bacia & & & & \\
\hline Aceguá & $1.551,33$ & 872,78 & 56 & 4.487 & 4.384 & $59.414,01$ & 0,742 \\
\hline Arroio do Padre & 124,69 & 67,07 & 54 & 2.784 & 1.585 & $20.601,76$ & 0,677 \\
\hline Arroio Grande & $2.514,76$ & $2.514,76$ & 100 & 18.013 & 18.013 & $34.065,27$ & 0,672 \\
\hline Bagé & $4.090,36$ & 31,54 & 1 & 120.104 & 22 & $25.150,78$ & 0,714 \\
\hline Candiota & 933,62 & 933,62 & 100 & 9.450 & 9.450 & $54.355,15$ & 0,730 \\
\hline Canguçu & $3.526,25$ & 951,36 & 27 & 53.121 & 33.923 & $21.452,83$ & 0,670 \\
\hline Capão do Leão & 785,37 & 785,37 & 100 & 26.524 & 26.524 & $20.704,39$ & 0,621 \\
\hline Cerrito & 451,69 & 451,69 & 100 & 6.043 & 6.043 & $16.246,46$ & 0,662 \\
\hline Chuí & 202,38 & 202,38 & 100 & 5.930 & 5.930 & $40.645,72$ & 0,754 \\
\hline Herval & $1.759,71$ & $1.759,71$ & 100 & 6.647 & 6.647 & $21.420,86$ & 0,664 \\
\hline Hulha Negra & 822,90 & 407,56 & 50 & 6.776 & 2.955 & $24.316,60$ & 0,643 \\
\hline Jaguarão & $2.052,41$ & $2.052,41$ & 100 & 27.393 & 27.393 & $26.185,34$ & 0,698 \\
\hline Morro Redondo & 244,64 & 244,64 & 100 & 6.621 & 6.621 & $13.634,41$ & 0,694 \\
\hline Pedras Altas & $1.373,98$ & $1.373,98$ & 100 & 2.048 & 100 & $52.096,98$ & 0,777 \\
\hline Pedro Osório & 608,81 & 608,81 & 100 & 7.999 & 7.999 & $18.955,62$ & 0,678 \\
\hline Pelotas & $1.609,70$ & $1.461,03$ & 91 & 341.166 & 340.630 & $25.307,60$ & 0,701 \\
\hline Pinheiro Machado & $2.248,22$ & 961,46 & 43 & 11.947 & 11.716 & $24.350,57$ & 0,659 \\
\hline Piratini & $3.537,79$ & $1.966,20$ & 56 & 18.990 & 18.039 & $20.771,08$ & 0,680 \\
\hline Rio Grande & $2.708,37$ & $2.708,37$ & 100 & 210.610 & 210.610 & $43.576,35$ & 0,718 \\
\hline Santa Vitória do Palmar & $5.195,66$ & $5.195,66$ & 100 & 31.208 & 31.208 & $30.432,72$ & 0,705 \\
\hline Turuçu & 253,63 & 134,82 & 53 & 3.721 & 1.035 & $26.188,66$ & 0,668 \\
\hline TOTAL & $37.200,78$ & $25.685,22$ & - & 921.582 & 770.827 & $29.741,11$ & - \\
\hline Rio Grande do Sul & $281.707,15$ & - & $13,21 \%$ & 11.329 .605 & - & $37.512,74$ & 0,754 \\
\hline Brasil & $8.510 .820,62$ & - & $0,30 \%$ & 208.494 .900 & - & $31.833,50$ & - \\
\hline
\end{tabular}

Fonte: Elaborado pelos autores a partir de FEE (2020).

Por sua vez, a região leste do Uruguai é uma área de baixa concentração populacional em termos relativos. A soma dos habitantes dos quatro departamentos localizados na bacia representa 12,4\% do total nacional (Quadro 2). Mais de 50\% da população total reside nas quatro capitais departamentais, o que demonstra 
uma forte concentração urbana. Além disso, apenas 6,5\% do total vivem em áreas rurais. Em relação à sua economia, essa região representa 4,8\% do PIB nacional, sendo que o setor primário representa, em média, 36,3\% do VAB total na região. Treinta y Tres é um dos departamentos com maior especialização agrícola, com o setor primário representando $44 \%$ de seu produto departamental total. Na região Leste, o setor industrial está ligado a iniciativas incipientes de agroindústrias em Rocha e Treinta y Tres. Podem-se mencionar, entre outros, os moinhos de arroz, as indústrias de embalagem de carne e laticínios (INE, 2011).

$\mathrm{Na}$ interface entre os países há setores com lógica própria claramente identificável. Os territórios fronteiriços, com características que podem ser reconhecidas a cerca de 150 quilômetros da linha de fronteira, apresentam forte ênfase nos aspectos locais, que originam expressões comunitárias únicas, como por exemplo: 1) culturalmente: gastronomia, tradições históricas, a música e a língua da fronteira; 2) socialmente: um entrelaçamento dos aspectos cotidianos e o uso das vantagens comparativas do trabalho ou da habitação em ambos os lados da fronteira; 3) comercialmente: uma intensa troca local de bens de consumo familiares, influenciada pelas condições econômicas, pela disponibilidade de certos itens e pelo valor da moeda; 4) nas políticas de desenvolvimento: situações que oscilam entre a falta de consideração da administração federal e as flutuações das decisões políticas internacionais, e o desenvolvimento de políticas e programas de fronteiras específicos, comumente originados de organizações setoriais de um país e de outro, que em alguns casos excede a importância local e atinge expressões em escala nacional.

Quadro 2 - Dados demográficos e econômicos uruguaios da Bacia Mirim-São Gonçalo

\begin{tabular}{|c|c|c|c|c|c|c|}
\hline \multirow{2}{*}{ DEPARTAMENTO } & \multicolumn{3}{|c|}{ Área } & \multirow{2}{*}{$\begin{array}{c}\begin{array}{c}\text { População } \\
\text { Total }\end{array} \\
2011\end{array}$} & \multirow{2}{*}{$\begin{array}{l}\text { PIB per capita } \\
\text { (UY\$) }\end{array}$} & \multirow{2}{*}{$\begin{array}{r}\text { IDH } \\
2017\end{array}$} \\
\hline & Total $\left(\mathrm{Km}^{2}\right)$ & $\begin{array}{c}\text { na Bacia } \\
\left(\mathrm{Km}^{2}\right)\end{array}$ & $\%$ na Bacia & & & \\
\hline Cerro Largo & 13.648 & 6.456 & 47 & 84.698 & $215.704,30$ & 0,783 \\
\hline Lavalleja & 10.016 & 7.167 & 72 & 58.815 & $276.626,40$ & 0.791 \\
\hline Maldonado & 4.793 & 1.074 & 22 & 168.298 & $335.617,20$ & 0,822 \\
\hline Rocha & 10.551 & 7.543 & 71 & 68.088 & $262.743,50$ & 0,784 \\
\hline Treinta y Tres & 9.676 & 9.283 & 96 & 48.134 & $251.936,10$ & 0,771 \\
\hline TOTAL & 48.684 & 31.523 & - & 428.033 & $268.525,50$ & - \\
\hline Uruguai & 176.220 & - & $17,88 \%$ & 3.449 .299 & $303.873,00$ & 0,804 \\
\hline
\end{tabular}

Fonte: Elaborado pelos autores a partir de INE (2011) e OTU (2019).

\section{Histórico da gestão compartilhada}

\section{A formação do território e os antecedentes da CLM}

Após os processos de independência e do estabelecimento das relações diplomáticas no século XIX, os Tratados de Limites de 1851 e de 1909 definiram 
a linha de fronteira entre Brasil e Uruguai (Pucci, 2010; Cervo; Bueno, 2011), compreendendo um total de $1.069 \mathrm{~km}$. A fronteira é caracterizada por extensões de área seca e outras de natureza fluvial e lacustre.

Para além das questões políticas nacionais, motivadas pela definição da posse de territórios ocupados ainda na época colonial, é importante recordar que a formação histórica da fronteira do extremo-sul do estado do RS se une à da República Oriental do Uruguai (Vianna, 2012), em decorrência do processo de regionalização observado (Hurrell, 2007). Tal processo foi caracterizado pelos contatos espontâneos de natureza social e econômica entre os habitantes da região ao longo de seu processo de formação, gerando traços culturais e identitários comuns as sociedades que ali estão. A cultura gaúcha ou gaucha, presente nos pampas rio-platenses, é produto da miscigenação entre os povos nativos e os invasores europeus, podendo ser analisada enquanto um fenômeno identitário de natureza transnacional (Cortesão, 2001; Ribeiro, 2006).

O Tratado de 1909 concedeu o direito à livre navegação no Rio Jaguarão e na Lagoa Mirim, que passaram a ser utilizados legalmente por brasileiros e uruguaios (Cervo; Bueno, 2011). Contudo, registros históricos mostram que desde 1779 o aproveitamento da Lagoa Mirim e da Laguna dos Patos despertava o interesse no desenvolvimento econômico da região (MRE, 1969).

Em 1961, o Conselho Nacional de Governo do Uruguai, visando à recuperação dos banhados do Departamento de Rocha, propôs ao Fundo Especial da ONU um pedido de assistência técnica para tratar de questões relacionadas aos usos da água da Lagoa Mirim. No mesmo ano os ministros de Relações Exteriores de Brasil e Uruguai se comprometeram a constituir uma comissão bilateral para tratar dos problemas relacionados à navegação na Lagoa Mirim e ao seu sistema hidrográfico (CLM, 1961; MRE, 1969).

\section{A constituição da CLM e as bases para a gestão compartilbada}

É interessante observar como a visão de bacia hidrográfica guiou os entendimentos entre Brasil e Uruguai na gestão compartilhada da Lagoa Mirim e seus afluentes já nessa época. Tal constatação é atestada pela assinatura das Notas Reversais que, em 1963, deu continuidade à institucionalização da cooperação bilateral na região, mediante a criação de uma comissão mista responsável por estudar "os problemas técnicos, econômicos e sociais relacionados com o melhoramento das condições de navegabilidade e aproveitamento total da Bacia da Lagoa Mirim integrada pela baixada sul-riograndense e pela parte situada em território uruguaio" (CLM, 1963, s. p.).

Dessa forma, desde sua origem, a Comissão Mista Brasileiro-Uruguaia para o Desenvolvimento da Bacia da Lagoa Mirim (CLM) fortaleceu o ideal da água como elemento integrador e potencializador do desenvolvimento conjunto das sociedades da faixa de fronteira. Tal percepção, baseada na integração e não na disputa, produziu uma imagem positiva acerca dos usos da água, contribuindo para a institucionalização de iniciativas como esta (CLM, 1963). 
Na primeira ação de trabalho no âmbito da CLM, em 1964, os dois governos apresentaram ao Fundo Especial da ONU uma proposta conjunta de cooperação técnica para realização de um projeto de desenvolvimento regional. No mesmo ano, uma comissão de especialistas da ONU visitou a região e analisou as possibilidades de atuação entre os dois governos. A partir de 1965 técnicos de diversas nacionalidades participaram dos levantamentos de dados executados pela Food and Agriculture Organization (FAO) (MRE, 1969). No total foram investidos mais de US\$ 3.126.200,00 (não corrigidos) pela FAO e pelos governos dos dois países, para a realização dos estudos de viabilidade econômica no território da bacia hidrográfica (Sudesul, 1974).

\section{As obras de infraestrutura, a CLM e o Tratado da Lagoa Mirim}

Partindo do princípio de que a agricultura seria a base do desenvolvimento regional, os estudos envolveram as áreas de hidrologia, topografia, geologia, cartografia, engenharia, agronomia, pecuária, bem como os aspectos sociais e econômicos relacionados aos usos da água. Motivados por fenômenos de estiagens e inundações, que se alternam no verão e no inverno, estes estudos buscaram compreender como a regulação do regime hidrográfico da Lagoa Mirim poderia contribuir para o desenvolvimento econômico regional (Sudesul, 1974).

Entre as preocupações desses estudos figuravam o controle da salinização de águas da Lagoa Mirim, o aproveitamento de terras, os sistemas de irrigação, o abastecimento de água, a geração de energia hidrelétrica, a regularização da navegação no corpo da lagoa e nas vias de acesso ao mar. Dentre as obras, foram identificados diversos locais para a construção de barragens, projetos de irrigação e a construção de um sistema de comportas, sendo este último destinado ao Canal São Gonçalo (Sudesul, 1974).

Em 1971, a Secretaria Executiva da CLM instituiu o Departamento da Lagoa Mirim (DLM), vinculado oficialmente à Superintendência do Desenvolvimento da Região Sul (Sudesul). O DLM, sediado na cidade de Pelotas (RS), foi o órgão operador das referidas obras por parte do governo brasileiro (Sudesul 1974; Vianna, 2012). A escolha da Sudesul não foi acaso, já que sua criação ocorreu na ditadura civil-militar no Brasil (1964-1985) e visou à promoção do desenvolvimento regional como forma de aumentar a presença do Estado nas diversas regiões do país. Dessa forma, a construção destas obras era uma estratégia de gerar desenvolvimento econômico a partir do setor primário exportador, e não à toa, o projeto regional de desenvolvimento da Lagoa Mirim se tornou um dos principais executados pela Sudesul (Goularti Filho et al., 2012).

Em 1972, com a entrega do Relatório Final pela FAO, os governos de Brasil e Uruguai viram a necessidade de amparar formalmente a atuação da CLM, que seguiria como executora do Projeto Regional da Lagoa Mirim (CLM/ FAO/PNUD). Assim, em 1977, para dar seguimento as obras previstas pelo projeto, Brasil e Uruguai assinaram o Tratado da Lagoa Mirim (Brasil, 1977). Nele há menção à melhoria das condições de vida das populações fronteiriças a 
partir da gestão integrada dos recursos hídricos, reforçando o papel institucional da CLM enquanto órgão promotor da cooperação e reconhecendo a bacia como um território com características geográficas próprias e comum ao território dos dois países. Dentre as obras, no Brasil destacaram-se a construção de uma barragem e distrito de irrigação no Arroio Chasqueiro e a construção de uma barragem-eclusa no Canal São Gonçalo para impedir a salinização da Lagoa Mirim e garantir uma imensa reserva de água doce para a região.

Com a extinção da Sudesul, em 1991, o DLM foi então incorporado ao ente federal mais próximo na região, isto é, a Universidade Federal de Pelotas (UFPel) - incluindo os servidores, o acervo técnico-científico, o patrimônio, e a administração da barragem-eclusa no Canal de São Gonçalo e da barragem e distrito de irrigação do Chasqueiro. Pouco depois, em 1994, foi criada na estrutura da UFPel a Agência de Desenvolvimento da Bacia da Lagoa Mirim (ALM), que desde 2002 é o órgão federal de apoio administrativo, técnico e financeiro e sede executiva da Seção Brasileira da CLM (Brasil, 1994, 2002).

Como visto, o fortalecimento das relações entre Uruguai e Brasil, no território dessa bacia transfronteiriça, se consolidou no tempo alicerçado na cooperação institucionalizada pela CLM e no Tratado da Lagoa Mirim. Atualmente a CLM é composta por uma Seção Brasileira, integrada pelo Ministério das Relações Exteriores (MRE), pelo Ministério do Desenvolvimento Regional (MDR), pelo Ministério do Meio Ambiente (MMA) e pela ALM; e por uma Delegación Uruguaya, integrada pelo Ministerio de Relaciones Exteriores (MRE), pela Dirección Nacional de Águas (Dinagua), pela Prefectura Nacional Naval (PNN) e pelo Ministerio de Transporte y Obras Públicas (MTOP) (Figura 2). A CLM busca se reunir anualmente, alternando os países a cada edição da reunião, com o objetivo de avaliar e encaminhar as ações de trabalho. Por ocasião da $119^{\circ}$ reunião da CLM, realizada em Montevidéu em julho de 2019, entre outros temas que serão tratados adiante, foi resgatado o histórico da cooperação bilateral e ressaltado que a vigência deste espaço institucional é um canal de promoção do desenvolvimento regional até os dias de hoje.

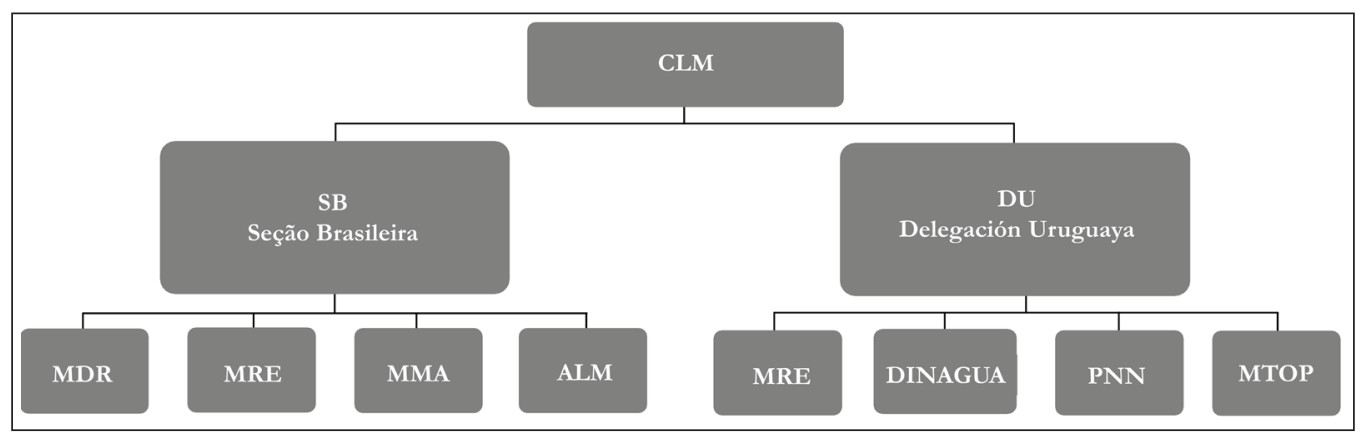

Fonte: Elaboração própria.

Figura 2 - Organograma da CLM. 


\section{A Agência de Desenvolvimento da Bacia da Lagoa Mirim-ALM}

Atuando sempre de forma articulada com os ministérios representados na Seção Brasileira da CLM, a ALM se configura como um organismo operativo e de apoio técnico. Ela é dirigida por uma Coordenação Geral (CG), sendo assessorada por uma Comissão Técnico-Científica-Administrativa Especial (CTC), e por um Conselho Consultivo (CC) (Figura 3).

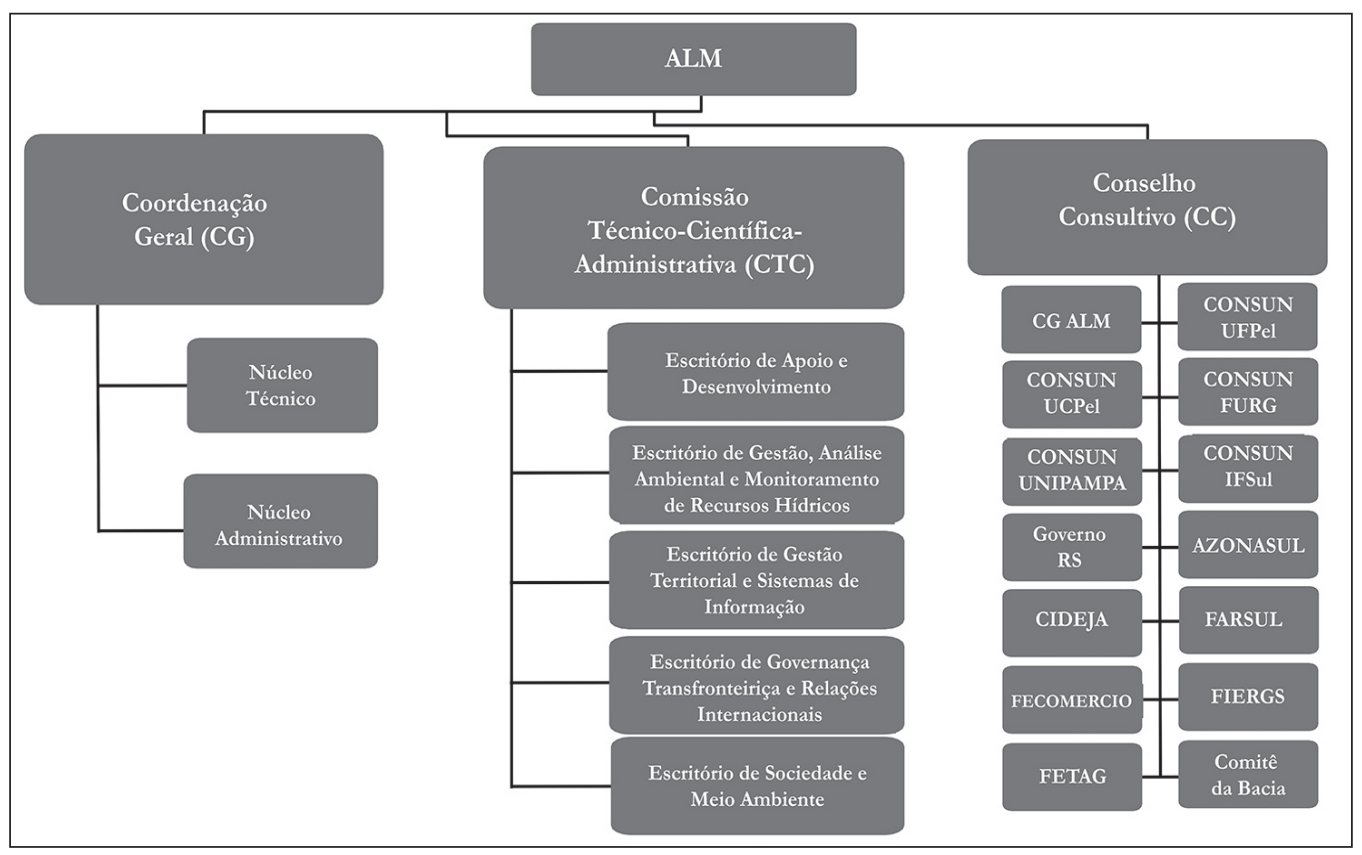

Fonte: Elaboração própria.

Figura 3 - Organograma da ALM.

Sob a gerência da coordenação geral, estão também o Núcleo Administrativo e o Núcleo Técnico, bem como a condução e operação da barragem-eclusa do Canal São Gonçalo; a administração da barragem e distrito de irrigação do Chasqueiro; e a operação da rede hidrometeorológica e de qualidade da água no Laboratório de águas e efluentes (Figura 4). Sob responsabilidade da CTC está a elaboração e execução de programas de Pesquisa, Ensino e Extensão, conectando as potencialidades da UFPel com demandas surgidas na bacia. O Conselho Consultivo é formado por 14 representantes de entidades e órgãos que tem relação direta com os objetivos da ALM (UFPel, 2019).

\section{A CTC, a gestão interdisciplinar e os eixos de ação da ALM}

A CTC é composta por docentes da UFPel especializados em diversas áreas do conhecimento e imbuídos da necessidade de um ambiente interdisciplinar de pesquisa e trabalho para atender as demandas das quais a ALM é responsável. Nesse sentido, a CTC objetiva: promover o apoio a gestão institucional; elaborar 
planos de trabalhos e projetos para o desenvolvimento regional e a integração; e planejar e executar ações referentes ao Tratado da Lagoa Mirim e planos de desenvolvimento binacionais. Para tanto a CTC é, atualmente, organizada em quatro escritórios que, ao mesmo tempo, desenvolvem ações independentes e concatenadas. Ademais, por meio do Escritório de Apoio e Desenvolvimento, a CTC busca integrar as estruturas de ensino e de pesquisa da UFPel através da capacitação de discentes em estágios institucionais de diferentes áreas do conhecimento.

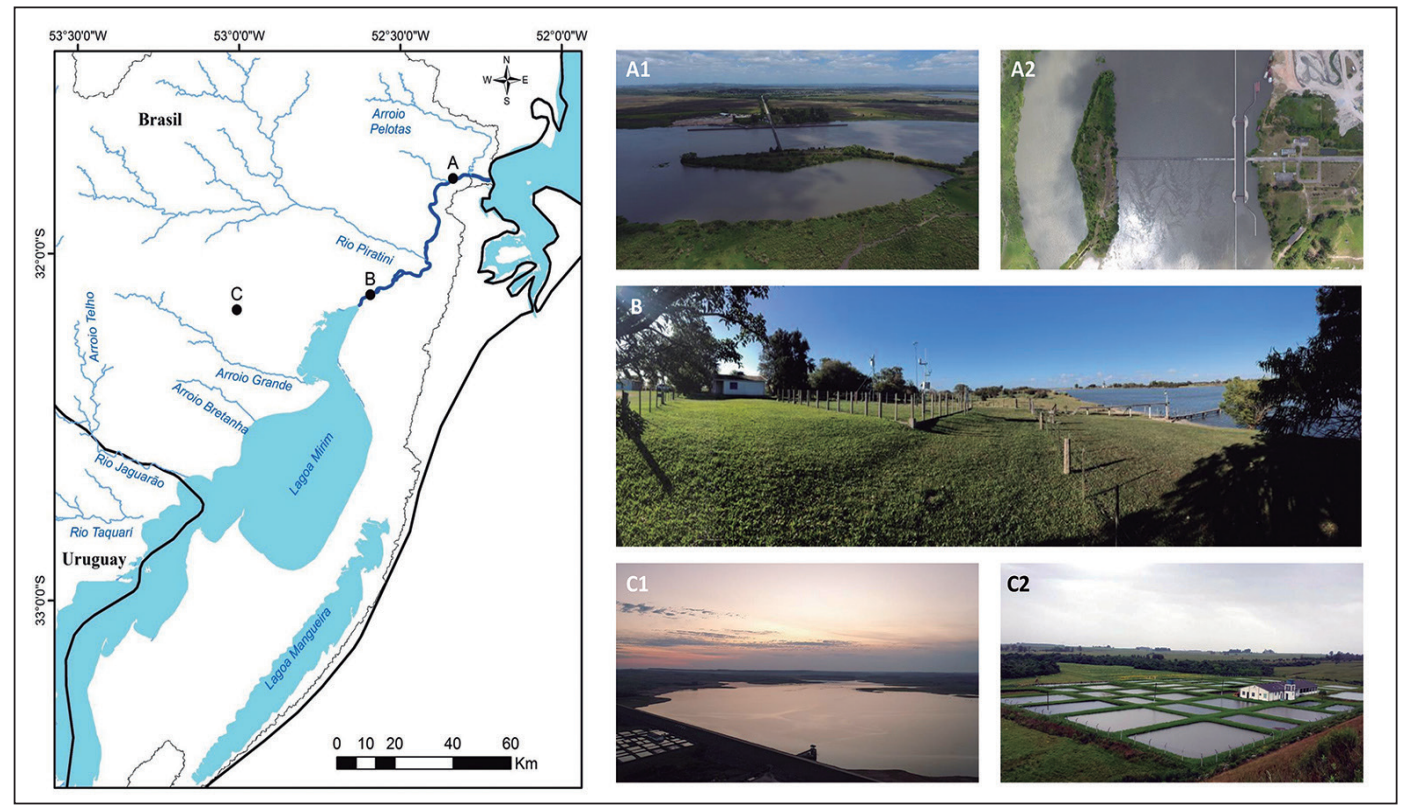

Fonte: Elaboração própria.

Figura 4 - Localização de estruturas administradas pela ALM: Al e A2 - Barragem- eclusa do São Gonçalo; B - Estação Hidrometeorológica e Hidrométrica de Santa Isabel; Cl - Barragem do Distrito de Irrigação do Chasqueiro e C2 - Estação de Aquicultura do Chasqueiro..

Considerando os temas apontados na agenda bilateral, a ALM busca desenvolver ações na forma de programas que permitam observar os recursos hídricos e seu potencial para o desenvolvimento sustentável. Entre eles está a execução de quatro programas de longa duração: "Programa de Desenvolvimento Regional em Aquicultura, Pesca e Turismo (PDRAPT)"; "Programa de Análise Ambiental e Monitoramento de Recursos Hídricos (PAAMRH)"; "Programa de Desenvolvimento das Capacidades Governativas (PDCG)"; e o "Programa de Fortalecimento Institucional da ALM (Pialm)".

\section{Escritório de Gestão, Análise Ambiental \\ e Monitoramento de Recursos Hidricos}

Esse escritório atua nos programas PDRAPT e PAAMRH em projetos como: fortalecimento da aquicultura como estratégia para o Desenvolvimento 
Regional; monitoramento da qualidade e quantidade de água na Bacia Mirim-São Gonçalo; o Laboratório de aquicultura da ALM; criação e distribuição de alevinos de espécies nativas; melhoramento de tilápias adaptadas ao clima frio; o Laboratório de águas e efluentes; as estações hidro meteorológicas; monitoramento hidrométrico, hidroquímico, climatológico e ambiental da bacia (Figura 5).

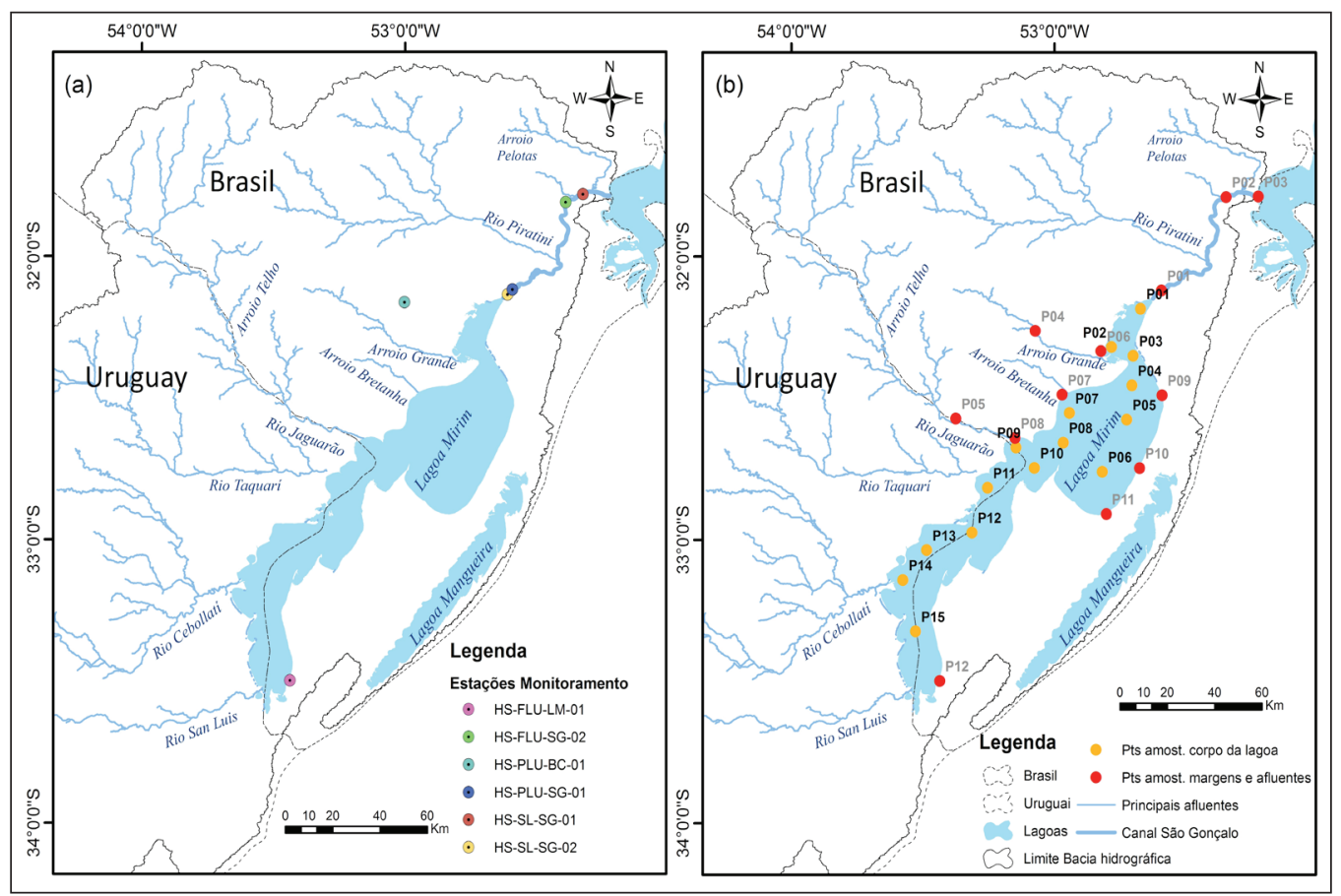

Fonte: Elaboração própria.

Figura 5 - A) Rede de Monitoramento Hidrométrico e Hidrológico; e B) Pontos de amostragem de qualidade de água na bacia.

\section{Escritório de Gestão Territorial e Sistemas de Informação}

Esse escritório atua nos programas PDRAPT e PAAMRH em projetos como: Zoneamento Ambiental da Bacia Hidrográfica Mirim-São Gonçalo; e Zoneamento Econômico Ecológico com olhar para a condição transfronteiriça da bacia.

\section{Escritório de Governança Transfronteiriça e Relações Internacionais}

Esse escritório por meio do Pialm assessora a CG nas atividades da ALM no âmbito da CLM e no relacionamento institucional com os demais membros da Seção Brasileira. O PDCG promove estudos para a melhoria da gestão compartilhada, por meio da análise da coordenação e articulação entre atores brasileiros e uruguaios na bacia. Busca atuar também no apoio às prefeituras e municípios na promoção da cooperação transfronteiriça. 


\section{Escritório de Sociedade e Meio Ambiente}

Esse escritório atua nos programas PDRAPT, PDCG e Pialm em projetos como: inventário dos bens de interesse cultural na bacia Mirim-São Gonçalo; execução do termo de cooperação com a Cooperativa de Pescadores de Santa Isabel; fortalecimento da cadeia produtiva do pescado; promoção da pesca artesanal via turismo: Rota do Peixe; e registro etnoarqueológico das práticas de pesca artesanal.

\section{As ações da CLM para o periodo 2019-2021}

$\mathrm{Na} 119^{\circ}$ reunião da CLM, em julho de 2019, foram tratados temas de interesse da agenda bilateral Brasil-Uruguai. Entre eles ganharam destaque a execução de obras de infraestrutura e os informes da secretaria técnica da Hidrovia Uruguai-Brasil. Também foram debatidas estratégias de manejo conjunto da bacia, com destaque para os temas da governança e da participação da sociedade civil, assim como da cooperação educacional binacional.

No que diz respeito à qualidade da água, foi instituído grupo de trabalho que tratará da harmonização das estratégias de coleta e análise laboratorial de amostras e de dados que são utilizados no monitoramento da qualidade da água no corpo hídrico da Lagoa Mirim e nos seus afluentes. A primeira reunião técnica dos grupos responsáveis por essas atividades (ALM e Dinagua), realizada em setembro de 2019 em Rio Branco (UY), definiu estratégias para realização de atividades conjuntas e comuns. Nesse sentido, os grupos técnicos de ambos os países programaram e executaram atividades conjuntas como, por exemplo, a primeira expedição embarcada na Lagoa Mirim, realizada em dezembro de 2019. Essa atividade caracteriza-se como marco inicial para a definição de estratégias comuns para um diagnóstico ambiental e para o planejamento compartilhado de gestão da bacia hidrográfica, observando seus usos, capacidades e fragilidades. Nessa expedição foram definidos os pontos de amostragens para análises de qualidade de água e sedimentos tanto na Lagoa como em seus afluentes, bem como avaliadas as melhores estratégias de um planejamento seguro para o monitoramento regular e permanente do sistema lagunar. Além dessas definições, foi possível apontar diretrizes para a harmonização dos protocolos de campo e de análises laboratoriais, definir parâmetros de interesse comum e por fim, criar as bases para um diagnóstico orientador de um planejamento de interesse comum aos usuários dessa bacia hidrográfica transfronteiriça.

\section{Discussão}

A Lagoa Mirim e o complexo de áreas úmidas de seu entorno formam uma das principais reservas de água doce transfronteiriças do continente, uma situação de grande importância econômica e ecológica para Brasil e Uruguai. $\mathrm{Na}$ década de 1970, pela cooperação internacional com a ONU, viabilizada pela CLM, foi estabelecido o primeiro plano de desenvolvimento regional transfronteiriço na América do Sul. 
O projeto centrou-se na construção de obras de infraestrutura voltadas ao aproveitamento dos recursos hídricos, com destaque para a agricultura irrigada e a captação de água para tratamento e distribuição nos aglomerados urbanos. No entanto, esses estudos não problematizaram a melhoria das condições ambientais da bacia, ou mesmo os impactos ambientais das obras de irrigação e das barragens nos ecossistemas e na qualidade da água. É imperativo contextualizar esse território no cenário geopolítico e apontar os distintos processos envolvidos, fundamentais para a compreensão da distribuição e variabilidade da fauna e flora local; da concentração de substâncias naturais na água (nutrientes, clorofila, material em suspensão); da presença de poluentes; dos processos de erosão, transporte de sedimentos e assoreamento; todos os fatores norteadores do desenvolvimento sustentável da bacia hidrográfica. Além da relevância ambiental, o conhecimento da dinâmica da bacia é de interesse econômico e estratégico para ambos os países, pois dele depende o emprego das águas para usos múltiplos, em especial na agricultura, no abastecimento público, e, não menos importante, no potencial hidroviário.

\section{A ALM e os desafios ao desenvolvimento regional}

Desde sua criação a ALM tem atuado de forma permanente no apoio as iniciativas concebidas pelos atores locais e suas estruturas sociais, com atenção ao desenvolvimento sustentável da bacia e regida pelos programas estatais que definem as relações políticas e administrativas de gestão pública integrada, diálogo e cooperação com o governo uruguaio.

Atualmente a concepção de desenvolvimento regional que orienta a ação da ALM considera a água como elemento primordial do processo de integração, ou seja, os cursos d'água e, em especial, a Lagoa Mirim, não são corpos que impõe limites, mas sim promovem conexões para as relações entre as comunidades, gerando potencialidades e desenvolvimento de estruturas de gestão binacional.

Cabe considerar que cada país tem regras e legislações próprias. No caso brasileiro a "Lei das Águas" instituiu a Política Nacional de Recursos Hídricos (PNRH) e criou o Sistema Nacional de Gerenciamento de Recursos Hídricos (Singreh) (Brasil, 1997). Essa lei estabelece elementos norteadores para os múltiplos usos da água, bem como responsabilidades e compromissos, prevendo que as consequências desses usos sejam capazes de apontar e dirimir conflitos, já que a água é um bem finito e a sociedade tem preocupações com a sua distribuição equitativa. Entre outros pontos, ela define que a água é um bem de domínio público; que a água é um recurso natural limitado, dotado de valor econômico; que em situações de escassez, o uso prioritário dos recursos hídricos é o consumo humano e animal; que a gestão dos recursos hídricos deve sempre proporcionar o uso múltiplo; que a bacia hidrográfica é a unidade territorial para implementação da PNRH e atuação do Singreh; e que a gestão dos recursos hídricos deve ser descentralizada e contar com a participação do poder público, dos usuários e das comunidades. 
Assim sendo, a política brasileira para os recursos hídricos estabelece a participação ativa da sociedade civil, e em especial a comunidade local, na construção e aprovação de um plano definidor dos usos atuais e futuros dos recursos hídricos. Para tanto, a sociedade civil deve estar organizada numa estrutura denominada Comitê de Bacias (CNRH, 2000). Essa estrutura se apresenta como um grupo de gestão, composto por representantes dos três níveis do poder público, usuários da água e entes sociedade civil. Por meio de discussões e negociações democráticas, os comitês avaliam os verdadeiros e distintos interesses sobre os usos das águas nas bacias hidrográficas. Eles possuem poder de decisão e cumprem papel fundamental no apontamento de políticas de gestão das bacias, sobretudo em regiões com problemas de escassez ou na qualidade da água. Como principais capacidades decisórias dos comitês de bacia estão a aprovação, elaboração e acompanhamento do Plano de Recursos Hídricos, que reúne informações estratégicas para a gestão das águas em cada bacia hidrográfica; além de arbitrar conflitos pelo uso da água e sugerir valores de cobrança pelo uso da água. Ao considerarmos que a bacia hidrográfica é um território que considera a água elemento integrador, o Comitê de Bacia Hidrográfica é um fórum em que os atores locais, com diferentes visões e atuações, promovem discussões sobre um interesse comum: os múltiplos usos da água.

Partindo dessas premissas, o Comitê de Gerenciamento da Bacia Hidrográfica Mirim-São Gonçalo, conceitualmente criado e concebido na ALM, conta com a participação de representantes dos usuários dos recursos hídricos, da sociedade civil e do poder público. A diretoria do comitê conta com o auxílio de uma Comissão Permanente de Assessoramento e de Grupos de Trabalho, que apoiam tecnicamente e cientificamente as deliberações (CMSG, 2007). A direta articulação entre o Comitê e a ALM se estabelece na orientação das diretrizes para a gestão das águas na bacia e nas discussões com os interlocutores sociais e usuários da água. Para tanto, a ALM está organizando e coletando informações que servirão de base para a elaboração do plano diretor para a bacia e que definirá as normas de usos dos recursos hídricos. Somado a isto, a pedido do governo estadual, será elaborado um diagnóstico da bacia apresentando uma caracterização geral, o arcabouço legal e institucional e a descrição dos atores relevantes para a gestão dos recursos hídricos, além da geração dos balanços hídricos quantitativos e qualitativos, apresentando como resultado a qualidade atual dos corpos hídricos na bacia.

Conceitualmente, a legislação brasileira está bastante próxima dos marcos regulatórios uruguaios. A criação da "Política Nacional de Aguas" (Uruguay, 2009) se assemelha à brasileira no que tange à sua integração com a política ambiental e a descentralização de gestão, tendo a bacia hidrográfica como base territorial das ações. Como resultado de um grande processo de construção, envolvendo órgãos estatais, técnicos, academia e a sociedade civil, em 2016 foi apresentado o "Plan Nacional de Aguas", um instrumento técnico e político para a planificação e gestão das águas considerando os mais diversos usos desse 
recurso (Uruguay, 2017). As legislações brasileira e uruguaia no que concernem ao planejamento dos usos da água em bacias hidrográficas possuem um grau de aproximação que potencializa a gestão compartilhada (Souza et al., 2014).

Por vezes, no entanto, a fronteira dificulta a coordenação dos usos da água quando não há uma harmonização entre os órgãos reguladores de ambos os países, como em relação a quantidade de água captada para cada finalidade nos diversos pontos da bacia, e em especial nas áreas limítrofes. O fortalecimento da coordenação com os atores responsáveis pelo monitoramento da qualidade e da quantidade de água é um desafio não somente em nível nacional, mas especialmente pela natureza transfronteiriça da bacia Mirim-São Gonçalo. A CLM, nesse sentido, é um espaço privilegiado para que a ALM possa em conjunto com o Dinagua construir estratégias unificadas de trabalho.

\section{Considerações finais}

Ao longo do texto observamos como se deu o processo de institucionalização da cooperação entre Brasil e Uruguai quanto aos usos da água na Bacia Hidrográfica Mirim-São Gonçalo. Visualizamos também como atualmente os atores públicos, em especial a ALM, tem atuado na promoção do desenvolvimento regional.

Os desafios para a gestão de recursos hídricos compartilhados tendem a ser reduzidos quando existem arranjos institucionais permanentes como os vistos aqui, capazes de promover a articulação entre os atores públicos e os entes da sociedade civil. Tal coordenação de ações é fundamental na promoção da cooperação, na prevenção de conflitos pelos usos da água e na busca por soluções conjuntas e coletivas essenciais para a gestão efetiva da bacia.

Nesse sentido, a CLM como uma experiência histórica e com vigência até os dias atuais, se apresenta como um mecanismo de construção de confiança e de continuidade dos esforços políticos para consolidação do desenvolvimento integrado da bacia. Por isso tudo, o braço operativo e técnico da CLM no Brasil, a ALM, busca atuar através de programas que sejam capazes de verificar os mananciais hídricos e seus potenciais para o desenvolvimento regional e sustentável. Entre as maiores responsabilidades da ALM estão o monitoramento integrado da qualidade da água na bacia hidrográfica; a elaboração e execução de estratégias para qualificar a gestão do território; e a promoção da gestão compartilhada sob a óptica transfronteiriça.

\section{Referências}

BRASIL. Tratado de Cooperação para o Aproveitamento dos Recursos Naturais e o Desenvolvimento da Bacia da Lagoa Mirim, 1977. Disponível em: <https://wp.ufpel.edu. $\mathrm{br} / \mathrm{alm} /$ files $/ 2019 / 07 /$ Tratado-de-Coopera\%C3\%A7\%C3\%A3o-para-o-Aproveitamento-dos-Recursos-Naturais-1977.pdf>. Acesso em: 19 abr. 2020.

Decreto n.1.148, de 26 de maio de 1994. Disponível em: <http://www.planalto.gov.br/ccivil_03/decreto/1990-1994/Dl148.htm>. Acesso em: 7 maio 2020.

Lei n.9.433, de 8 de janeiro de 1997. Disponível em: <http://www.planalto. gov.br/ccivil_03/LEIS/L9433.htm>. Acesso em: 30 nov. 2019. 
Decreto n.4.258, de 4 de junho de 2002. Disponível em: <https://presrepublica.jusbrasil.com.br/legislacao/99170/decreto-4258-02>. Acesso em: 7 maio 2020. CERVO, A. L.; BUENO, C. História da politica exterior do Brasil. Brasília: 4.ed. Brasília: Edit. UnB, 2011.

COMISSÃO MISTA BRASILEIRO-URUGUAIA. (CLM). Acta de Conversaciones Uruguay-Brasil de 1961. Arquivo ALM.

COMISSÃO MISTA BRASILEIRO-URUGUAIA. (CLM). Notas Reversais de 26 de abril de 1963. Disponível em: <https://wp.ufpel.edu.br/alm/files/2019/06/Notas-Reversais-entre-Brasil-e-Uruguai-estabelece-a-CLM-1963.pdf>. Acesso em: 10 set. 2019.

COMITÊ DE GERENCIAMENTO DA BACIA HIDROGRÁFICA MIRIM-SÃO GONÇALO (CMSG). Regimento Interno do Comitê de Gerenciamento das Bacias Hidrográficas da Lagoa Mirim e do Canal São Gonçalo. 2007. Disponível em: <http:// www.comitemirim.org.br/Arquivos/7/Documentos-Constituicao-Comite>. Acesso em: 29 abr. 2020.

CONSELHO NACIONAL DE RECURSOS HÍDRICOS (CNRH). Resolução n.5, de 10 de abril de 2000. Disponível em: <http://www.sema.df.gov.br/wp-conteudo/ uploads/2017/09/Resolu\%C3\%A7\%C3\%A3o-CNRH-n\%C2\%BA-5-de-2000.pdf>. Acesso em: 7 maio 2020.

CORDEIRO, J. L. P.; HASENACK, H. Cobertura vegetal atual do Rio Grande do Sul. In: PATTA PILLAR, V. et al. (Ed.) Campos Sulinos - conservação e uso sustentável da biodiversidade. Brasília: MMA, 2009. p.285-99.

CORTESÃO, J. O Tratado de Madri. Tomo II. Brasília: Senado Federal, 2001.

FUNDAÇÃO DE ECONOMIA E ESTATÍSTICA (FEE). Compilação de dados da Bacia Hidrográfica Mirim-São Gonçalo: Relatório para ALM. Porto Alegre, 2020.

GOES FILHO, S. S. Navegantes, Bandeirantes e Diplomatas: um ensaio sobre a formação das fronteiras no Brasil. Brasília: Funag, 2015.

GOULARTI FILHO, A., ALMEIDA, A. S.; MESSIAS, T. A. Sudesul: suas concepções de desenvolvimento e suas estratégias no processo de planejamento 1956-1989, 2012. Disponível em: <http://www.abphe.org.br/arquivos/alcides-goularti-filho-andre-scholl-de-almeida-talita-alves-de-messias.pdf>. Acesso em: 15 maio 2020.

GOUVÊA, T.; ZARNOT, D. H.; ALBA, J. M. F. Caracterização geoambiental e histórico do processo de desenvolvimento da bacia da Lagoa Mirim. In: FILIPPINI ALBA, J. M. (Ed.). Sustentabilidade socioambiental da bacia da Lagoa Mirim. Pelotas: Embrapa, 2010. p.19-30.

HURRELL, A. One world? Many worlds? The place of regions in the study of international society. International Affairs, v.83, n.1, p.127-46, 2007.

INSTITUTO NACIONAL DE ESTADISTICA (INE). Censos 2011. Montevideo. Uruguay. Disponível em: <http://www.ine.gub.uy/censos-201l>. Acesso em: 6 maio 2020 .

MINISTÉRIO DO MEIO AMBIENTE (MMA). Avaliação e ações prioritárias para a conservação da biodiversidade da Mata Atlântica e Campos Sulinos. Brasília: MMA/ SBF, 2000. 40p. 
MINISTÉRIO DAS RELAÇÕES EXTERIORES (MRE). Embaixada do Brasil em Montevidéu. El plan de desarrollo de la cuenca de la Laguna Merín. Departamento de Promoción Comercial, 1969.

OBSERVATORIO TERRITORIO URUGUAY (OTU). Indice de Desarrollo Humano por Departamento. 2019. Disponível em: <https://otu.opp.gub.uy/sites/default/ files/docsBiblioteca/IDH\%20-\%20S\%C3\%ADntesis\%20metodol\%C3\%B3gica $\% 20 y \% 20$ de\%20resultados_2.pdf>. Acesso em: 6 maio 2020.

OliveIRA, H. A. et al. Processos Hidrológicos e Hidrodinâmicos da Lagoa Mirim. Revista Brasileira de Recursos Hidricos, v.20, n.1, p.34-45, 2015.

PROBIDES Plan Director. Reserva de Biosfera Bañados del Este / Uruguay. Rocha: Probides, 1999. 159p.

PUCCI, A. S. O Estatuto da Fronteira Brasil-Uruguai. Brasília: Funag, 2010.

RIBEIRO, D. O povo brasileiro: a formação e o sentido do Brasil. São Paulo: Cia. das Letras: 2006.

SANT'ANNA, F. M. Governança Global dos Recursos Hídricos Transfronteiriços: o papel da cooperação internacional e da cooperação transfronteiriça. In: $3^{\circ}$ ENCONTRO NACIONAL DA ASSOCIAÇÃO BRASILEIRA DE RELAÇÕES INTERNACIONAIS, 2011, São Paulo. Governança Global e novos atores, 2011.

SECRETARIA DE MEIO AMBIENTE DO ESTADO DO RIO GRANDE DO SUL (SEMA). Departamento de Recursos Hidricos e Saneamento - DRHS: Bacias Hidrográficas. Disponível em: <https://www.sema.rs.gov.br/1040-bacia-hidrografica-da-lagoa-mirim-e-do-canal-sao-goncalo>. Acesso em: 20 abr. 2020.

SOUZA, M. et al. Governança de recursos comuns: bacias hidrográficas transfronteiriças. Revista Brasileira de Politica Internacional, n.57, v.2, p.152-75, 2014.

SUDESUL. Plano de Desenvolvimento da Bacia da Lagoa Mirim. Porto Alegre, 1974.

. Plano Diretor Básico Para Desenvolvimento da Bacia da Lagoa Mirim. Relatório Final. Hidroservice, São Paulo, 1975.

TUCCI, C. E.M. Hidrologia: ciência e aplicação. 2.ed. Porto Alegre: Ed. Universidade UFGRS, 2001. Coleção ABRH de Recursos Hídricos: v.4.

UNIVERSIDADE FEDERAL DE PELOTAS (UFPel). Resolução n.11, de 7 de agosto de 2019. Regimento da Agência da Lagoa Mirim. Disponível em: <https://wp.ufpel.edu.br/alm/files/2019/09/Resolu\%C3\%A7\%C3\%A3o-11-2019 SEI_23110.035285_2019_76.pdf>. Acesso em: 20 abr. 2020.

URUGUAY. Lei 18.160, de 2 de outubro de 2009. Disponível em: <https://www. impo.com.uy/bases/leyes/18610-2009>. Acesso em: 7 maio 2020.

. Plan Nacional de Aguas. 2017. Disponível em: <http://www.mvotma.gub. uy/politica-nacional-de-aguas/plan-nacional-de-aguas>. Acesso em: 7 maio 2020.

VIANNA, M. L. Extremo Sul do Brasil: um lugar esquecido. Pelotas: Editora Textos, 2012.

YASSUDA, E. R. Gestão de recursos hídricos: fundamentos e aspectos institucionais. Revista de Administração Pública, Rio de Janeiro, v.27, n.2, p.5-18, mai. 1993. 
RESUMO - O texto apresenta o contexto ambiental e socioeconômico da Bacia Hidrográfica Mirim-São Gonçalo e os aspectos políticos da sua natureza transfronteiriça. Também são ilustrados marcos institucionais e legais pioneiros de gestão compartilhada desse recurso hídrico expressos pela criação da Comissão Mista Brasileiro-Uruguaia para o Aproveitamento da Bacia da Lagoa Mirim (CLM) e pela assinatura do Tratado da Lagoa Mirim. Por fim, é apresentada a Agência para o Desenvolvimento da Lagoa Mirim (ALM), ator público presente no território, e como sua atuação pode robustecer o modelo de gestão existente ao promover e aprofundar a coordenação com os demais atores públicos e a sociedade civil.

PALAVRAS-CHAVE: Bacia Hidrográfica Mirim-São Gonçalo, Gestão compartilhada, Águas internacionais, Brasil, Uruguai.

ABSTRACT - This text presents the environmental and socioeconomic context of the Mirim-São Gonçalo hydrographic basin and the political aspects of its cross-border nature. Pioneering institutional and legal frameworks for shared management of this water resource are also illustrated, as expressed by the creation of the Mixed Brazilian-Uruguayan Commission for the Use of the Mirim Lagoon Basin (CLM) and the signature of the Mirim Lagoon Basin Treaty. Finally, the article presents the Agency for the Development of Mirim Lagoon (ALM), a public player active in the region, and how its performance can strengthen the existing management model by promoting and enhancing coordination with other public players and civil society.

KErWORDS: Mirim-São Gonçalo Basin, Shared management, International waters, Brazil, Uruguay.

Fernanda de Moura Fernandes atua no Escritório de Governança Transfronteiriça e Relações Internacionais da ALM; Professora adjunta do Instituto de Filosofia, Sociologia e Política, Universidade Federal de Pelotas (Ifisp-UFPel). @ - fernandamf.alm.ufpel@gmail.com / https://orcid.org/0000-0002-2312-6314.

Gilberto Loguercio Collares é diretor da ALM e secretário executivo da Seção Brasileira da CLM; Professor titular do Centro de Desenvolvimento Tecnológico, Universidade Federal de Pelotas (CDTec-UFPel). @ - collares@ufpel.edu.br / https://orcid.org/0000-0003-4910-5420.

Rafael Corteletti atua no Escritório de Sociedade e Meio Ambiente da ALM; Professor adjunto do Instituto de Ciências Humanas, Universidade Federal de Pelotas (ICHUFPel). @ - rcorteletti@ufpel.edu.br / https://orcid.org/0000-0001-5606-9910.

Recebido em 15.6.2020 e aceito em 22.10.2020.

I Universidade Federal de Pelotas, Instituto de Filosofia, Sociologia e Política, Pelotas, Rio Grande do Sul, Brasil.

II Universidade Federal de Pelotas, Centro de Desenvolvimento Tecnológico, Pelotas, Rio Grande do Sul, Brasil.

III Universidade Federal de Pelotas, Instituto de Ciências Humanas, Pelotas, Rio Grande do Sul, Brasil. 
